which were deprived of their cotyledons at a suitable stage, when they contained about ninety per cent of the total vitamin C present in the seedling. Such seedlings generally die or remain completely dwarfed, whereas they will develop distinctly better, and even produce normal blossoms, when small amounts of pure ascorbic acid are added to the medium. Even the treated plants naturally suffer from the removal of cotyledons, which evidently contain also other necessary compounds besides vitamin C. The accom. panying table will illustrate the effect of ascorbic acid on the development of cotyledon-less seedlings. dynamics, attracted attention by uitımately blessing them : which led to an invasion into Great Britain that I tried in my own way to counter by a critical commentary in my "Mathematical and Physical Papers" (vol. 2, pp. 603-7; 1928).

The fragmentary treatments by Kelvin and Rankine, even by Maxwell and Willard Gibbs, may be deficient as regards formal logic, but after all they are the efforts of constructive genius in this universal subject, after Carnot. Even the reviewer admits that it is hard to find English equivalents for the German technical terms. Indeed, the logical flavour comes largely from treating thermodynamics as a branch of the statistical mechanics as developed after Maxwell and Boltzmann: while on the other hand no biologist ought to admit that the vital activities to which he applies thermodynamic principles can be adequately described by the mere statistical play of atoms in the main unknown. It is here that the merit of Clausius' introduction of his concept of an abstract universal entropy, as the necessary correlative of unavoidable universal temperature, shines, however unfinished be its present state of development.

It is therefore reasonable to regard vitamin $\mathrm{C}$ as a phytohormone, which is indispensable to plants. The formation of vitamin $\mathrm{C}$ during germination is necessary for the early development of the plant. During later stages of growth, large quantities of vitamin $\mathrm{C}$ are produced in connexion with photosynthesis. So far, vitamin $\mathrm{C}$ is the only vitamin the indispensability of which to higher plants has been proved through direct experiments. Corresponding work on vitamin $B_{2}$ (lactoflavine) is at present in progress in this laboratory.

W. H. Schopfer ${ }^{5}$ has recently shown that vitamin $\mathrm{B}_{1}$ promotes greatly the growth of lower fungi (Phycomyces, etc.). According to his results, the effect is very delicate and specific, so that it can be used for the quantitative determination of $B_{1}$.

The fact that certain compounds, which act as vitamins in the animal organism, have important functions in plants, is additional evidence of the similarity of the metabolism of plant and animal cells.

Biochemical Institute, ArtTURi I. Virtanen.

Helsingfors.

March 30.

1 Virtanen, v. Hausen and Saastamoinen, Ann. Acad. Scient. Fenn., A, 37, No. 7 (1933).

Scheunert, Sachse and Specht, Biochem. Z., 274, 373 (1934). 3 v. Hausen, Suomen Kemistilehti, B, Nos. 5-6 (1935); o. 12 (1935); NATURE, 136, 516 (1935).

' Havas, Nature, 136, 435 (1935).

5 Schopfer, ref. Karrer, Schweiz. Mediz. Wochenschr., 65, No. 37 (1935).

\section{Formal and Practical Thermodynamics}

MAy I put in a word for the British way of looking at thermodynamics, now largely confined to engineers, as suggested by the critical remarks on the second edition of the treatise of Prof. Saha and Dr. Srivas. tava, contained in the brilliant and appreciative review in NaTuRE of April 4. Especially would I firmly support the Indian authors in passing over the preliminary abstractions of Prof. Carathéodory of Munich and his school. I remember when Prof. Planck, in a new edition of his book on thermo-
Incidentally one may note that the statistical equipartition of energy between the 'momentoids' of the molecules, even when they do not represent momenta, was settled long ago in general discussion between Rayleigh, Bryan and Boltzmann.

Holywood, Co. Down. JOSEPH LARMOR. April 5.

\section{Terminology of Relative Growth}

THe quantitative study of relative growth and the proportion of parts has in recent years made considerable progress, and is now beginning to find widespread application in such diverse fields as systematics, embryology, genetics and palæontology, as well as in growth-studies proper. Unfortunately, serious diversities of terminology and notation have sprung up $^{1,2,3,4,5,6}$. We therefore wish to propose the following agreed terminology to avoid confusion. be dropped. Dysharmony was first used to denote the exaggerated proportions of certain organs, and a suggestion of abnormality remains attached to it. Heterogony has been widely used to denote a certain type of reproductive cycle ${ }^{9,10,11}$, so that its employ. ment in a new sense is not desirable. Accordingly, to denote growth of a part at a different rate from that of body as a whole or of a standard, we propose the term allometry, with isometry for the special case where the growth-rate of the part is identical with that of the standard or whole. Allo. metry has the advantage of recalling the allometrons of Osborn ${ }^{12}$, those gradual changes in proportion observed in evolution, which according to the work of Herseh ${ }^{13}$ and Robb ${ }^{14}$ do proceed according to our fundamental law of allometric growth. The ${ }^{-}$term has the further advantage that it can be applied equally legitimately to phenomena of growth (dysharmonie de croissance) or to those of proportionate size (dysharmonie de taille) as in holomets. bolous insects. Positive and negative allometry denoto respectively growth-rates of the part above or below that of the standard.
(1) The terms dysharmony $y^{7}$ and heterogony ${ }^{8}$ should 